\title{
Épocas de Aplicação de Penoxsulam e de Início da IRRigação no ARROZ IRRIGADO ${ }^{1}$
}

\author{
Effects of Penoxsulam Application Timings and Initial Flood on Irrigated Rice
}

\author{
AGOSTINETTO, D. ${ }^{2}$, PANOZZO, L.E. ${ }^{3}$, MORAES, P.V.D. ${ }^{4}$, DAL MAGRO, T. ${ }^{5}$, TAROUCO, C.P. ${ }^{6}$, \\ OLIVEIRA, C. ${ }^{7}$ e RUBIN, R. ${ }^{8}$
}

\begin{abstract}
RESUMO - O arroz irrigado está sujeito à interferência causada por fatores bióticos e abióticos; entre os primeiros, as plantas daninhas são as principais responsáveis pela redução na produtividade, interferindo diretamente nos componentes do rendimento do cereal. Objetivouse avaliar o efeito de épocas de início de irrigação por inundação, época de aplicação e doses de penoxsulam sobre os componentes da produtividade de grãos de arroz irrigado, cultivar Qualimax 1. O experimento foi instalado em campo, em delineamento experimental de blocos ao acaso com parcelas subsubdivididas e quatro repetições. Nas parcelas alocaram-se as épocas de aplicação (precoce e tardia) do herbicida penoxsulam; nas subparcelas, as épocas de início da irrigação $(1,15$ e 30 dias após a aplicação dos herbicidas - DAT); e nas subsubparcelas, as doses do herbicida $\left(0,24,36,48\right.$ e $\left.60 \mathrm{~g} \mathrm{ha}^{-1}\right)$. A maior produtividade de grãos da cultura foi obtida quando se aplicou o herbicida penoxsulam nas doses iguais ou superiores a $36 \mathrm{~g} \mathrm{ha}^{-1}$, independentemente da época de aplicação, e quando a irrigação foi realizada nas épocas iniciais. A antecipação da irrigação incrementa os componentes do rendimento de grãos de arroz, cultivar Qualimax 1. A aplicação de penoxsulam em doses iguais ou superiores a $36 \mathrm{~g} \mathrm{ha}^{-1}$, independentemente da época de aplicação ou de inundação, não modifica os componentes de rendimento do arroz irrigado.
\end{abstract}

Palavras-chave: Cyperus esculentus, controle químico, Echinochloa sp., Oryza sativa

\begin{abstract}
Irrigated rice is subject to interference caused by biotic and abiotic factors. Among the former, weeds are the main causes of decreased productivity, directly interfering in rice yield. The objective of this study was to evaluate the effect of irrigation starting times, application times and penoxsulam rates on the yield components of irrigated rice, cultivar Qualimax 1. The experiment was installed in the field, in a randomized block design with split plots and four replications. The plots allocated application dates (early and late) of Penoxsulam, and the subplots the starting times of irrigation (1, 15 and 30 days after herbicide application-DAT) and the split-split herbicide doses $\left(0,24,36,48\right.$ and $\left.60 \mathrm{~g} \mathrm{ha}^{-1}\right)$. The highest grain yield was obtained by applying penoxsulam at the rates of $36 \mathrm{~g} \mathrm{ha}^{-1}$ or above, regardless of the application time, and when early irrigation was carried out. The anticipation of irrigation generally increases the yield components of rice cultivar Qualimax 1. The application of penoxsulam at equal doses or higher than $36 \mathrm{~g} \mathrm{ha}^{-1}$, regardless of application dates or flood, do not change the yield components of irrigated rice.
\end{abstract}

Keywords: Cyperus esculentus, chemical control, Echinochloa sp., Oryza sativa.

1 Recebido para publicação em 15.5.2010 e na forma revisada em 6.5.2011.

2 Engo-Agr ${ }^{\circ}$., Dr., Professor da Faculdade de Agronomia Eliseu Maciel, Universidade Federal de Pelotas - UFPel; ${ }^{3}$ Eng ${ }^{0}$-Agr ${ }^{0}$., aluno do Programa de Pós-Graduação em Fitotecnia, Universidade Federal de Viçosa - DFT/UFV, 36570-000 Viçosa-MG, $<$ lepanozzo@gmail.com>; ${ }^{4}$ Engo--Agr $^{\circ}$., D.Sc. Pós-Doutorado em Fitotecnia, University of Kentucky - UK; ${ }^{5}$ Engo-Agr ${ }^{\circ}$., Dr., Professor, Universidade de Caxias do Sul - UCS; ${ }^{6}$ Eng $^{-}-$Agr $^{\circ}$., aluna do Programa de Pós-Graduação em Fitossanidade, UFPel; ${ }^{7}$ Aluna de Agronomia, Faculdade de Agronomia Eliseu Maciel, UFPel; ${ }^{8}$ Eng - -Agr ${ }^{\circ} .$, , M.Sc., Pesquisador Dow AgroSciences 


\section{INTRODUÇÃO}

$\mathrm{O}$ arroz irrigado está sujeito à interferência causada pelas plantas daninhas, as quais podem ser responsáveis pela redução na produtividade, interferindo diretamente nos componentes de rendimento do cereal. Entre as práticas culturais utilizadas para controlar as plantas daninhas nas lavouras de arroz irrigado, destaca-se o manejo da irrigação, o qual envolve procedimentos considerados importantes, seja do ponto de vista econômico ou cultural (Gomes et al., 2005). Esse manejo pode aumentar a atividade de herbicidas, possibilitando uma ação mais eficiente sobre as plantas daninhas, como também impede a emergência de novos fluxos de plantas daninhas nas áreas inundadas - fator determinante para a obtenção de alta produtividade de grãos (Fleck et al., 2004; Concenço et al., 2006).

Considerando os aspectos ligados a otimização do uso da água, impacto ambiental, custo da energia, infestação e controle de plantas daninhas e ecofisiologia da cultura, existem controvérsias sobre o momento ideal de início de irrigação. Tradicionalmente, nas lavouras do Rio Grande do Sul (RS), a irrigação do arroz inicia-se aos 30 dias após a emergência (DAE) das plantas, o que acontece, em média, 15 a 30 dias após a aplicação dos herbicidas (SOSBAI, 2007), período em que a produtividade de grãos normalmente não é alterada, desde que ocorra precipitação regular (Andres \& Machado, 2004).

Por outro lado, a produtividade de grãos da cultura é reduzida com o atraso da irrigação além do período recomendado ou com a redução das doses dos herbicidas residuais (Gomes et al., 1999). Nesse sentido, Andres et al. (2007) observaram redução de até $20 \%$ no rendimento de grãos do arroz em função do atraso da irrigação de 20 para 35 DAE. De modo similar, Menezes et al. (2003) observaram que o atraso de 20 dias no início da irrigação, após a aplicação do herbicida, diminuiu a produtividade de grãos, o número de panículas e o número de grãos por panícula e prolongou o ciclo da cultura. Já Pinto et al. (2008) constataram perdas de produtividade de grãos de arroz na ordem de $57 \%$ ao retardarem a entrada de água na lavoura em 10 dias.
Independentemente do sistema de cultivo do arroz, o controle químico é a principal ferramenta de manejo de plantas daninhas, em razão da eficiência, rapidez, praticidade, uniformidade de controle e menor custo, comparativamente a outros métodos de controle. Contudo, a eficiência de controle varia de acordo com a espécie, com o manejo adotado na lavoura, com a tecnologia de aplicação e com a dose do herbicida utilizado. Ressalta-se também que poucos herbicidas apresentam ação residual de solo suficiente para evitar a reinfestação da área, especialmente em solos de topografia ondulada, a qual dificulta a manutenção de lâmina de água uniforme.

Entre os herbicidas com ação residual de solo disponiveis no mercado encontra-se o penoxsulam, pertencente ao grupo das triazolopirimidinas sulfonamidas, que atua na inibição da enzima acetolactato sintase (ALS). Essa enzima é responsável pela formação dos aminoácidos de cadeia ramificada valina, leucina e isoleucina (Eberlein et al., 1997; Zabalza et al., 2004; Damalas et al., 2006). Os herbicidas inibidores da ALS caracterizam-se por serem efetivos em doses reduzidas e possuírem amplo espectro de controle (Ottis et al., 2003; Jabusch \& Tjeerdema, 2005), baixa toxicidade ao homem e aos animais (Brown, 1990; Newhouse et al., 1991; Sprague et al., 1997), sendo registrado para aplicação em pré e pós-emergência (SOSBAI, 2007). Em razão de seu amplo espectro de ação, controlando diversas espécies daninhas, e também pela ação residual de solo, o penoxsulam tornou-se um dos herbicidas mais utilizados nas lavouras de arroz do RS.

Nesse contexto, objetivou-se com este trabalho avaliar o efeito de épocas de início de irrigação por inundação, época de aplicação e doses de penoxsulam sobre os componentes da produtividade de grãos de arroz irrigado, cultivar Qualimax 1.

\section{MATERIAL E MÉTODOS}

O experimento foi instalado em campo, em sistema de cultivo mínimo, na Granja Quatro Irmãos, município de Rio Grande-RS, ano agrícola 2005/2006. O solo da área é classificado como Planossolo Hidromórfico Eutrófico solódico, pertencente à Unidade de 
Mapeamento Pelotas (Embrapa, 2006). A adubação foi realizada de acordo com análise do solo, sendo utilizados $200 \mathrm{~kg} \mathrm{ha}^{-1}$ da formulação 5-20-20 na semeadura e $100 \mathrm{~kg} \mathrm{ha}^{-1} \mathrm{de}$ nitrogênio $(\mathrm{N})$, fracionados em aplicações no início do afilhamento e na emissão do primórdio foliar (36 e $60 \mathrm{DAE}$ ).

O delineamento experimental utilizado foi de blocos ao acaso com parcelas subsubdivididas, com quatro repetições. Nas parcelas principais, com área de $225 \mathrm{~m}^{2}$, alocaram-se as épocas de aplicação do penoxsulam (precoce e tardia); nas subparcelas, com área de $75 \mathrm{~m}^{2}$, as épocas de entrada de água na lavoura (1, 15 e 30 dias após a aplicação dos herbicidas DAT); e nas subsubparcelas, com área de $15 \mathrm{~m}^{2}$, dispuseram-se as doses do herbicida $(0$, $24,36,48$ e $\left.60 \mathrm{~g} \mathrm{ha}^{-1}\right)$.

O cultivar Qualimax 1 foi semeado na densidade de $150 \mathrm{~kg} \mathrm{ha}^{-1}$, proporcionando o estabelecimento de população aproximada de 400 plantas $\mathrm{m}^{-2}$, com espaçamento entre linhas de 0,17 m. Esse cultivar foi escolhido em função de ser um dos mais cultivados na região sul do Estado do RS, local de condução do experimento. A água de irrigação foi mantida na área experimental em torno de 25 dias antes da colheita do arroz - época esta recomendada como a ideal para a remoção dela da lavoura sem prejuízos à cultura (SOSBAI, 2007).

Para a aspersão do herbicida, utilizou-se pulverizador costal pressurizado a $\mathrm{CO}_{2}$ com barra de $2 \mathrm{~m}$ de comprimento e, acopladas a esta, quatro pontas de pulverização da série XR 110.02, trabalhando em pressão de

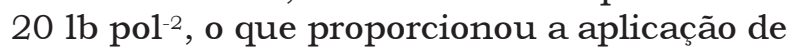
volume de calda herbicida de $150 \mathrm{~L} \mathrm{ha}^{-1}$. No momento da primeira aplicação (precoce), as plantas de arroz encontravam-se em estádio de 2-4 folhas; as de C. esculentus, com 4-5 folhas; e as de Echinochloa spp., com 1-3 folhas. Já para a segunda aplicação (tardia), o arroz encontrava-se com 4 folhas a 1 afilho; as plantas de $C$. esculentus, com 6 a 8 folhas; e Echinochloa spp., com 4 folhas a 2 afilhos. A população das espécies daninhas foi de 161 e 524 plantas $\mathrm{m}^{-2}$ para C. esculentus e Echinochloa spp., respectivamente.

Para a determinação do número de grãos cheios e número de espiguetas por panícula, coletaram-se 10 panículas da área útil de cada unidade experimental. Posteriormente, cada panícula foi debulhada manualmente, efetuando-se a contagem dos grãos cheios e estéreis por panícula, sendo a soma resultante no número de espiguetas. A produtividade de grãos do arroz foi quantificada pela colheita da área central das subsubparcelas de $3 \mathrm{~m}^{2}$ ( $3 \times 1 \mathrm{~m})$, quando o teor de umidade deles aproximou-se de $22 \%$. Após a pesagem dos grãos, foi determinada a umidade; os dados, corrigidos para $13 \%$; e a produtividade, expressa em $\mathrm{kg} \mathrm{ha}^{-1}$. O peso de mil grãos foi quantificado pela contagem manual de seis amostras de 100 grãos, sendo o valor expresso em $\mathrm{g}$.

Os dados de produtividade de grãos, peso de mil grãos, grãos cheios e espiguetas foram analisados quanto à sua homocedasticidade e normalidade e, posteriormente, submetidos à análise da variância $(p \leq 0,05)$. A comparação das médias para os fatores qualitativos foi efetuada pelo teste de Tukey $(p \leq 0,05)$. Para o fator quantitativo, utilizou-se a análise de regressões por meio de modelos lineares e não lineares $(p \leq 0,10)$, levando-se em conta a significância estatística $(F)$, o ajuste $r^{2}$ e a explicação do fenômeno biológico destes (Adati et al., 2006).

\section{RESULTADOS E DISCUSSÃO}

Houve interação entre os fatores testados para todas as variáveis estudadas. A influência de épocas de aplicação do penoxsulam para a variável produtividade demonstrou, em geral, não haver diferença entre a aplicação precoce e tardia do herbicida, independentemente da época de início da irrigação e das doses testadas (Tabela 1). Esses resultados podem decorrer do curto intervalo de tempo entre as duas épocas de aplicação.

Os resultados demonstram que o atraso no início da irrigação por inundação em 30 DAT, quando comparada com 1 e 15 DAT, reduziu a produtividade de grãos da cultura, na aplicação em estádio tardio, para todas as doses de herbicida testadas (Tabela 1). Na média, a antecipação em 14 e 29 dias no início da irrigação, em relação à primeira época, aumentou a produtividade de grãos, respectivamente, em cerca de 17 e 19\% para a aplicação precoce e em 10 e $42 \%$ para a tardia. 
Tabela 1 - Produtividade de grãos de arroz irrigado $\left(\mathrm{kg} \mathrm{ha}^{-1}\right)$, cultivar Qualimax 1, em função de épocas de início da irrigação, épocas de aplicação e doses do herbicida penoxsulam. Granja Quatro Irmãos, Rio Grande-RS, 2005/2006

\begin{tabular}{|c|c|c|c|}
\hline Dose & \multicolumn{3}{|c|}{ Época de Irrigação } \\
\hline$\left(\mathrm{g} \mathrm{ha}^{-1}\right)$ & $1 \mathrm{DAT}$ & $15 \mathrm{DAT}$ & $30 \mathrm{DAT}$ \\
\hline & \multicolumn{3}{|c|}{ Precoce } \\
\hline 0 & $7.475 \mathrm{Aa}^{1 /}$ & $3.706 \mathrm{Ab}$ & $3.431 \mathrm{Ab}$ \\
\hline 24 & $8.289 \mathrm{Aa}$ & $8.015 \mathrm{Aa}$ & $7.093 \mathrm{Aa}$ \\
\hline 36 & $9.678 \mathrm{Aa}$ & $8.461 \mathrm{Aa}$ & $9.195 \mathrm{Aa}$ \\
\hline 48 & $9.751 \mathrm{Aa}$ & $9.400 \mathrm{Aa}$ & $8.695 \mathrm{Aa}$ \\
\hline 60 & $9.107 \mathrm{Aa}$ & $8.456 \mathrm{Aa}$ & $8.945 \mathrm{Aa}$ \\
\hline \multicolumn{4}{|c|}{ Tardio } \\
\hline 0 & $4.431 \mathrm{Ba}$ & $3.585 \mathrm{Aab}$ & $2.105 \mathrm{Ab}$ \\
\hline 24 & $8.659 \mathrm{Aa}$ & $8.027 \mathrm{Aa}$ & $6.022 \mathrm{Ab}$ \\
\hline 36 & $8.900 \mathrm{Aa}$ & $8.672 \mathrm{Aa}$ & $6.055 \mathrm{Bb}$ \\
\hline 48 & $8.997 \mathrm{Aa}$ & $7.583 \mathrm{Bab}$ & $6.847 \mathrm{Bb}$ \\
\hline 60 & $9.872 \mathrm{Aa}$ & $9.136 \mathrm{Aab}$ & $7.687 \mathrm{Ab}$ \\
\hline
\end{tabular}

${ }^{1 /}$ Médias seguidas por letras distintas, maiúsculas na coluna e minúsculas na linha, diferem entre si pelo teste de Tukey $(\mathrm{p} \leq 0,05)$

Resultados demonstram redução de até $20 \%$ na produtividade de grãos do arroz em função do atraso da irrigação de 20 para $35 \mathrm{DAE}$ (Andres et al., 2007). Nesse mesmo sentido, Panozzo et al. (2009) observaram que o atraso do início da irrigação por inundação reduziu a produtividade dessa cultura. A antecipação do início da irrigação para 1, 10 ou 20 dias após a aplicação dos herbicidas aumentou a produtividade de grãos de arroz em competição com Echinochloa spp. (Galon et al., 2007a). Em estudo que avaliou os efeitos de épocas de início de irrigação, épocas de aplicação e dose do penoxsulam, foi verificado que o atraso em 10 dias do início da irrigação após a aplicação deste herbicida reduziu em média $41 \%$ a produtividade de grãos de arroz (Pinto et al., 2008). As perdas de produtividade em função do atraso da irrigação podem aumentar com a redução da aplicação de herbicidas residuais (Concenço et al., 2006; Pinto et al., 2008; Panozzo et al., 2009).

A competição de uma planta de capimarroz $\mathrm{m}^{-2}$, durante todo o ciclo de desenvolvimento da cultura do arroz irrigado, causou perdas variáveis de 4 a 30\% (Galon et al., 2007a,b; Agostinetto et al., 2007). Segundo esses autores, essas perdas são decorrentes principalmente da variedade de arroz utilizada, da época de início da irrigação na lavoura e também da época de aplicação do herbicida. Ainda, a ausência de controle das plantas daninhas durante o ciclo de desenvolvimento do arroz irrigado pode ocasionar perdas no rendimento de grãos na ordem de 80 a 90\% (Andres \& Machado, 2004).

O fator dose do herbicida penoxsulam, em geral, demonstrou bom ajuste dos dados ao modelo, à exceção da primeira época de irrigação na aplicação precoce, a qual apresentou ajuste de 0,40 (Figura 1). O aumento das doses do herbicida incrementou a produtividade de grãos, tendendo a estabilizar-se acima de $36 \mathrm{~g} \mathrm{ha}^{-1}$, independentemente da época de aplicação e quando a irrigação iniciou-se em
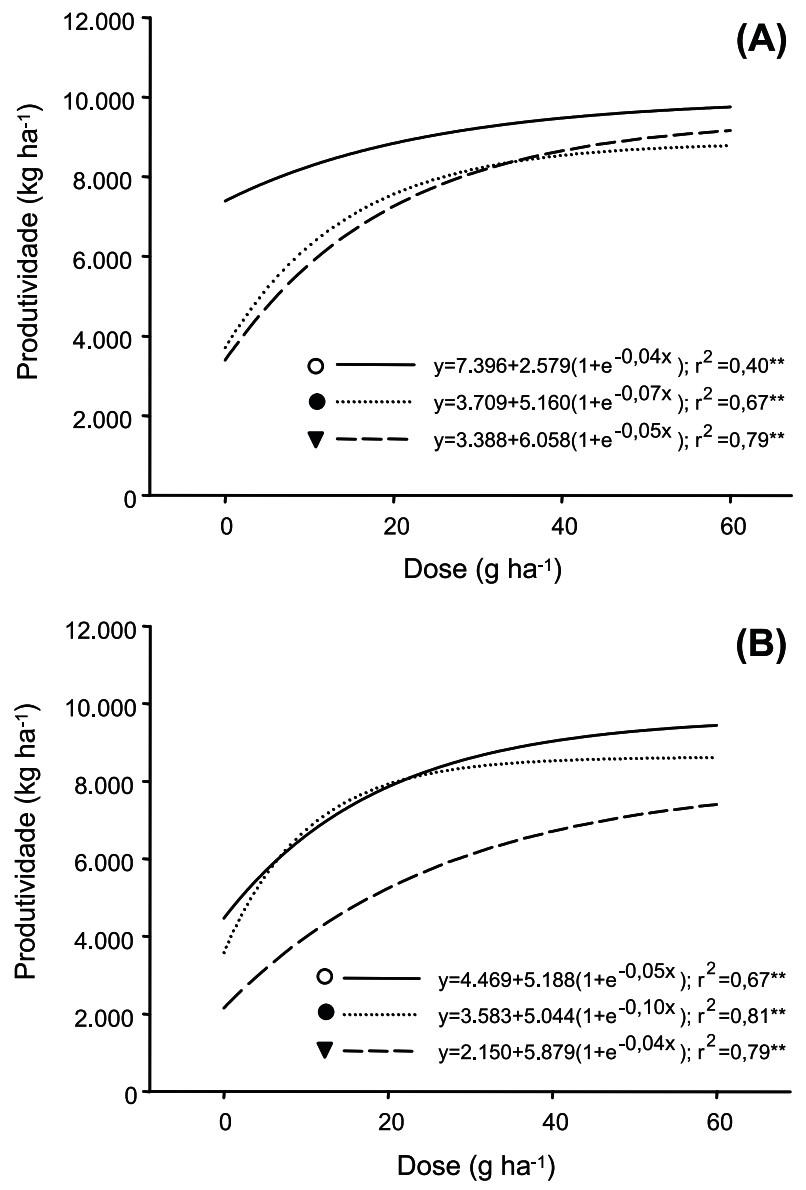

$\mathrm{r}^{2}$ : coeficiente de determinação; significativo a $\mathrm{p} \leq 0,10$.

Figura 1 - Produtividade de grãos do cultivar de arroz irrigado Qualimax 1, em função de épocas de início da irrigação (1 DAT, O15 DAT e $\boldsymbol{\nabla} 30$ DAT), épocas de aplicação precoce (A) e tardia (B) e doses do herbicida penoxsulam. Granja Quatro Irmãos, Rio Grande-RS, 2005/2006. 
período de até 15 DAT. Esses resultados podem decorrer da eficiência de controle das plantas daninhas $C$. esculentus e Echinochloa spp. obtida com doses de penoxsulam iguais ou superiores a $36 \mathrm{~g} \mathrm{ha}^{-1}$.

Para a variável peso de mil grãos, constatou-se que o atraso do início da irrigação quando a aplicação do herbicida foi realizada em estádio precoce, independentemente da dose utilizada, diminuiu o peso de grãos (Tabela 2). Já a comparação entre as épocas de aplicação, para todas as doses testadas, apresentou aumento na aplicação precoce quando o início da irrigação foi feito logo após a aplicação do herbicida.

Os resultados demonstraram que a aplicação precoce, associada à antecipação do início da irrigação, incrementa o peso de mil grãos na ordem de 3,8 e $3,4 \%$, na comparação das médias de todas as épocas de início de irrigação aos 15 e 30 DAT, respectivamente (Tabela 2). A aplicação precoce do herbicida, associada ao início da irrigação em 1 DAT, resultou em incremento médio de $5 \%$ do peso de mil grãos, comparativamente à aplicação tardia. Esses resultados podem decorrer da rápida ação do herbicida promovida pela antecipação da irrigação, diminuindo o período de convivência da cultura com as plantas daninhas.

Tabela 2 - Peso de mil grãos de arroz irrigado (g), cultivar Qualimax 1, em função de épocas de início da irrigação, épocas de aplicação e doses do herbicida penoxsulam. Granja Quatro Irmãos, Rio Grande-RS, 2005/2006

\begin{tabular}{|c|c|c|c|}
\hline Dose & \multicolumn{3}{|c|}{ Época de Irrigação } \\
\hline$\left(\mathrm{g} \mathrm{ha}^{-1}\right)$ & $1 \mathrm{DAT}$ & $15 \mathrm{DAT}$ & $30 \mathrm{DAT}$ \\
\hline & \multicolumn{3}{|c|}{ Precoce } \\
\hline 0 & $27,3 \mathrm{Aa}^{\underline{1}}$ & $25,8 \mathrm{Ab}$ & $26,1 \mathrm{Ab}$ \\
\hline 24 & $27,3 \mathrm{Aa}$ & $26,4 \mathrm{Ab}$ & $26,3 \mathrm{Ab}$ \\
\hline 36 & $27,6 \mathrm{Aa}$ & $26,8 \mathrm{Ab}$ & $26,9 \mathrm{Ab}$ \\
\hline 48 & $27,7 \mathrm{Aa}$ & $27,0 \mathrm{Ab}$ & $26,8 \mathrm{Ab}$ \\
\hline 60 & $27,7 \mathrm{Aa}$ & $26,6 \mathrm{Ab}$ & $26,8 \mathrm{Ab}$ \\
\hline & & Tardio \\
\hline 0 & $25,9 \mathrm{Ba}$ & $25,9 \mathrm{Aa}$ & $25,9 \mathrm{Aa}$ \\
\hline 24 & $26,2 \mathrm{Ba}$ & $26,6 \mathrm{Aa}$ & $26,2 \mathrm{Aa}$ \\
\hline 36 & $26,4 \mathrm{Ba}$ & $26,5 \mathrm{Aa}$ & $26,1 \mathrm{Ba}$ \\
\hline 48 & $26,3 \mathrm{Ba}$ & $26,5 \mathrm{Aa}$ & $26,1 \mathrm{Ba}$ \\
\hline 60 & $26,4 \mathrm{Ba}$ & $26,8 \mathrm{Aa}$ & $26,4 \mathrm{Aa}$ \\
\hline
\end{tabular}

1/ Médias seguidas por letras distintas, maiúsculas na coluna e minúsculas na linha, diferem entre si pelo teste de Tukey $(\mathrm{p} \leq 0,05)$.
Os efeitos de doses do herbicida ajustaram-se ao modelo linear, porém com baixos valores de $\mathrm{r}^{2}$ (Figura 2). Ainda, na comparação entre épocas de irrigação, tendo por base os valores da inclinação da reta, constatou-se que a maior resposta a doses do herbicida foi obtida quando o início de irrigação ocorreu aos 15 DAT, permitindo inferir que a irrigação iniciada precocemente (1 DAT) exerce efeito supressor das plantas daninhas, minimizando o efeito de doses do herbicida. Já na irrigação tardia (30 DAT) não há efeito físico da lâmina de água, o que reduz a resposta de doses do herbicida.
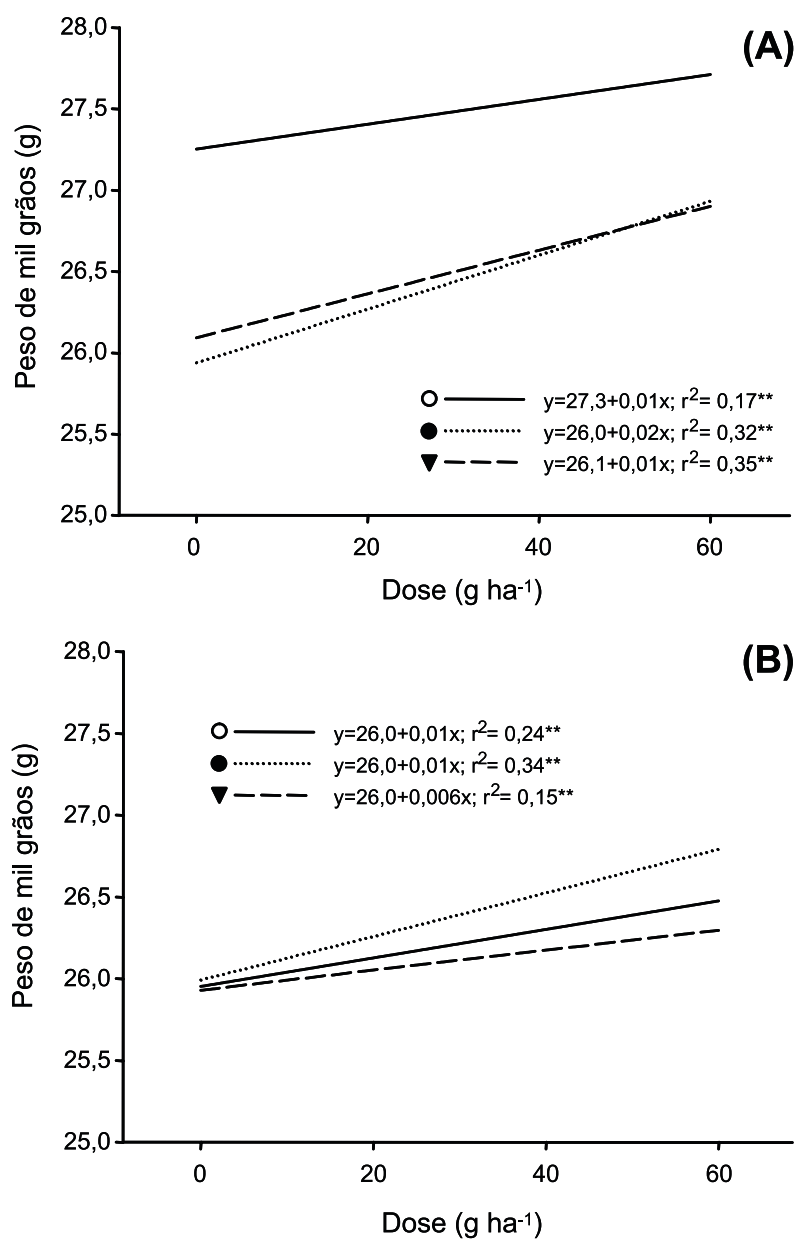

$\mathrm{r}^{2}$ : coeficiente de determinação; significativo a $\mathrm{p} \leq 0,10$.

Figura 2 - Peso de mil grãos de arroz irrigado, cultivar Qualimax 1, em função de épocas de início da irrigação $(1$ DAT, O15 DAT e $\boldsymbol{\nabla} 30$ DAT), épocas de aplicação precoce (A) e tardia (B) e doses do herbicida penoxsulam. Granja Quatro Irmãos, Rio Grande-RS, 2005/2006. 
Para a variável número de grãos cheios por panícula, verificou-se que as doses de 48 e $60 \mathrm{~g}$ do herbicida penoxsulam, aplicado em estádio precoce de desenvolvimento das plantas daninhas, associado ao início da irrigação aos 30 DAT, reduziram o número de grãos cheios por panícula (Tabela 3 e Figura 3). Já para a aplicação tardia do herbicida, independentemente das épocas de início da irrigação e doses testadas, em geral, não se observou aumento no número de grãos cheios por panícula.

A antecipação da irrigação na ausência do herbicida (testemunha) proporcionou incremento do número de grãos cheios quando a aplicação foi realizada em estádio precoce, comparativamente ao estádio tardio (Tabela 3). Esses resultados podem ser decorrentes do efeito causado pela presença de lâmina de água, que impede a emergência de novos fluxos de plantas daninhas, reduzindo a competição pelos recursos do meio e/ou o efeito fisiológico na planta.

O fator dose do herbicida penoxsulam, para a variável número de grãos cheios, demonstrou baixo ajuste dos dados ao modelo, na época de aplicação precoce do herbicida, e bom ajuste para aplicação tardia (Figura 3).

Tabela 3 - Número de grãos cheios de arroz por panícula, cultivar Qualimax 1, em função de épocas de início da irrigação, épocas de aplicação e doses do herbicida penoxsulam. Granja Quatro Irmãos, Rio Grande-RS, 2005/2006

\begin{tabular}{|c|c|c|c|}
\hline Dose & \multicolumn{3}{|c|}{ Época de Irrigação } \\
\hline$\left(\mathrm{g} \mathrm{ha}^{-1}\right)$ & $1 \mathrm{DAT}$ & $15 \mathrm{DAT}$ & $30 \mathrm{DAT}$ \\
\hline & \multicolumn{3}{|c|}{ Precoce } \\
\hline 0 & $80,8 \mathrm{Aa}^{\underline{1}}$ & $57,5 \mathrm{Ab}$ & $66,7 \mathrm{Aab}$ \\
\hline 24 & $93,9 \mathrm{Aa}$ & $95,0 \mathrm{Aa}$ & $88,6 \mathrm{Aa}$ \\
\hline 36 & $95,5 \mathrm{Aa}$ & $93,8 \mathrm{Aa}$ & $96,4 \mathrm{Aa}$ \\
\hline 48 & $94,2 \mathrm{Aa}$ & $89,8 \mathrm{Aab}$ & $77,2 \mathrm{Ab}$ \\
\hline 60 & $92,0 \mathrm{Aab}$ & $98,0 \mathrm{Aa}$ & $80,0 \mathrm{Ab}$ \\
\hline & & Tardio \\
\hline 0 & $59,2 \mathrm{Ba}$ & $62,4 \mathrm{Aa}$ & $57,8 \mathrm{Aa}$ \\
\hline 24 & $92,9 \mathrm{Aa}$ & $96,4 \mathrm{Aa}$ & $86,0 \mathrm{Aa}$ \\
\hline 36 & $92,4 \mathrm{Aa}$ & $97,2 \mathrm{Aa}$ & $92,9 \mathrm{Aa}$ \\
\hline 48 & $104,4 \mathrm{Aa}$ & $87,2 \mathrm{Ab}$ & $85,2 \mathrm{Ab}$ \\
\hline 60 & $90,9 \mathrm{Aa}$ & $89,6 \mathrm{Aa}$ & $90,4 \mathrm{Aa}$ \\
\hline
\end{tabular}

1/ Médias seguidas por letras distintas, maiúsculas na coluna e minúsculas na linha, diferem entre si pelo teste de Tukey $(\mathrm{p} \leq 0,05)$.
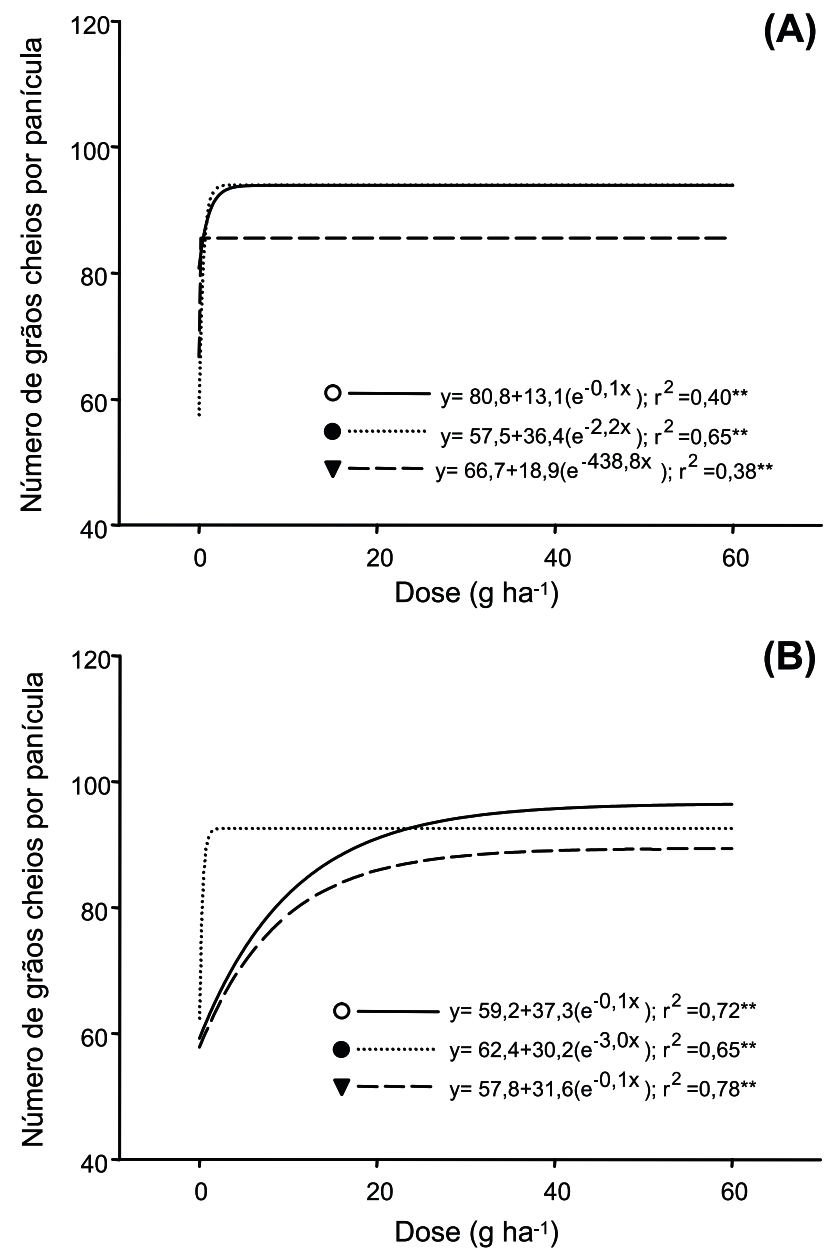

$\mathrm{r}^{2}$ : coeficiente de determinação; significativo a $\mathrm{p} \leq 0,10$.

Figura 3 - Número de grãos cheios de arroz por panícula, cultivar Qualimax 1, em função de épocas de início da irrigação (1 DAT, O15 DAT e $\boldsymbol{\nabla} 30$ DAT), épocas de aplicação precoce (A) e tardia (B) e doses do herbicida penoxsulam. Granja Quatro Irmãos, Rio Grande-RS, 2005/2006.

O aumento das doses dos herbicidas incrementou o número de grãos cheios por panícula, tendendo a estabilizar-se nas doses superiores a $36 \mathrm{~g} \mathrm{ha}^{-1}$, independentemente da época de aplicação ou de irrigação por inundação. Esses resultados podem ser decorrentes do fato de a referida dose apresentar controle eficiente das plantas daninhas, conforme discutido anteriormente. Corroborando esses resultados, Panozzo et al. (2009) observaram incremento na cultura do arroz em doses iguais ou superiores a $36 \mathrm{~g} \mathrm{ha}^{-1}$ do herbicida penoxsulam. 
De modo semelhante ao verificado para a variável número de grãos cheios, as maiores doses de penoxsulam, aplicado em estádio precoce e com irrigação tardia, reduziram o número de espiguetas por panícula (Tabela 4 e Figura 4). Na comparação entre as épocas de aplicação, em geral, não se observou diferença entre os tratamentos (Tabela 4).

O fator dose do herbicida penoxsulam, para a variável número de espiguetas por panícula, demonstrou bom ajuste dos dados ao modelo, à exceção da primeira e terceira épocas de irrigação na aplicação precoce, as quais apresentaram baixo ajuste ao modelo (Figura 4).

A maior produtividade de grãos da cultura foi obtida quando se aplicou o herbicida penoxsulam nas doses iguais ou superiores a $36 \mathrm{~g} \mathrm{ha}^{-1}$, independentemente da época de aplicação e quando a irrigação foi realizada nas épocas iniciais. A antecipação da irrigação incrementa os componentes do rendimento de grãos de arroz, cultivar Qualimax 1. A aplicação de penoxsulam em doses iguais ou superiores a $36 \mathrm{~g} \mathrm{ha}^{-1}$, independentemente da época de aplicação ou de inundação, não modifica os componentes de rendimento do arroz irrigado.

Tabela 4 - Número de espiguetas de arroz por panícula, cultivar Qualimax 1, em função de épocas de início da irrigação, épocas de aplicação e doses do herbicida penoxsulam. Granja Quatro Irmãos, Rio Grande-RS, 2005/2006

\begin{tabular}{|c|c|c|c|}
\hline Dose & \multicolumn{3}{|c|}{ Época de Irrigação } \\
\hline$\left(\mathrm{g} \mathrm{ha}^{-1}\right)$ & $1 \mathrm{DAT}$ & $15 \mathrm{DAT}$ & $30 \mathrm{DAT}$ \\
\hline & \multicolumn{3}{|c|}{ Precoce } \\
\hline 0 & $99,5 \mathrm{Aa}^{1 /}$ & $82,8 \mathrm{Ab}$ & $87,0 \mathrm{Aa}$ \\
\hline 24 & $113,2 \mathrm{Aab}$ & $122,9 \mathrm{Aa}$ & $106,3 \mathrm{Ab}$ \\
\hline 36 & $123,3 \mathrm{Aa}$ & $118,0 \mathrm{Aa}$ & $128,4 \mathrm{Aa}$ \\
\hline 48 & $113,1 \mathrm{Bab}$ & $117,4 \mathrm{Aa}$ & $100,2 \mathrm{Ab}$ \\
\hline 60 & $103,7 \mathrm{Ab}$ & $125,7 \mathrm{Aa}$ & $98,1 \mathrm{Ab}$ \\
\hline & \multicolumn{4}{|c|}{ Tardio } \\
\hline 0 & $81,4 \mathrm{Ba}$ & $80,8 \mathrm{Aa}$ & $67,7 \mathrm{Ba}$ \\
\hline 24 & $114,3 \mathrm{Aab}$ & $121,5 \mathrm{Aa}$ & $100,1 \mathrm{Ab}$ \\
\hline 36 & $120,9 \mathrm{Aa}$ & $117,8 \mathrm{Aa}$ & $112,0 \mathrm{Aa}$ \\
\hline 48 & $127,8 \mathrm{Aa}$ & $113,6 \mathrm{Aab}$ & $102,8 \mathrm{Ab}$ \\
\hline 60 & $111,9 \mathrm{Aa}$ & $113,3 \mathrm{Aa}$ & $107,3 \mathrm{Aa}$ \\
\hline
\end{tabular}

1/ Médias seguidas por letras distintas, maiúsculas na coluna e minúsculas na linha, diferem entre si pelo teste de Tukey $(\mathrm{p} \leq 0,05)$.
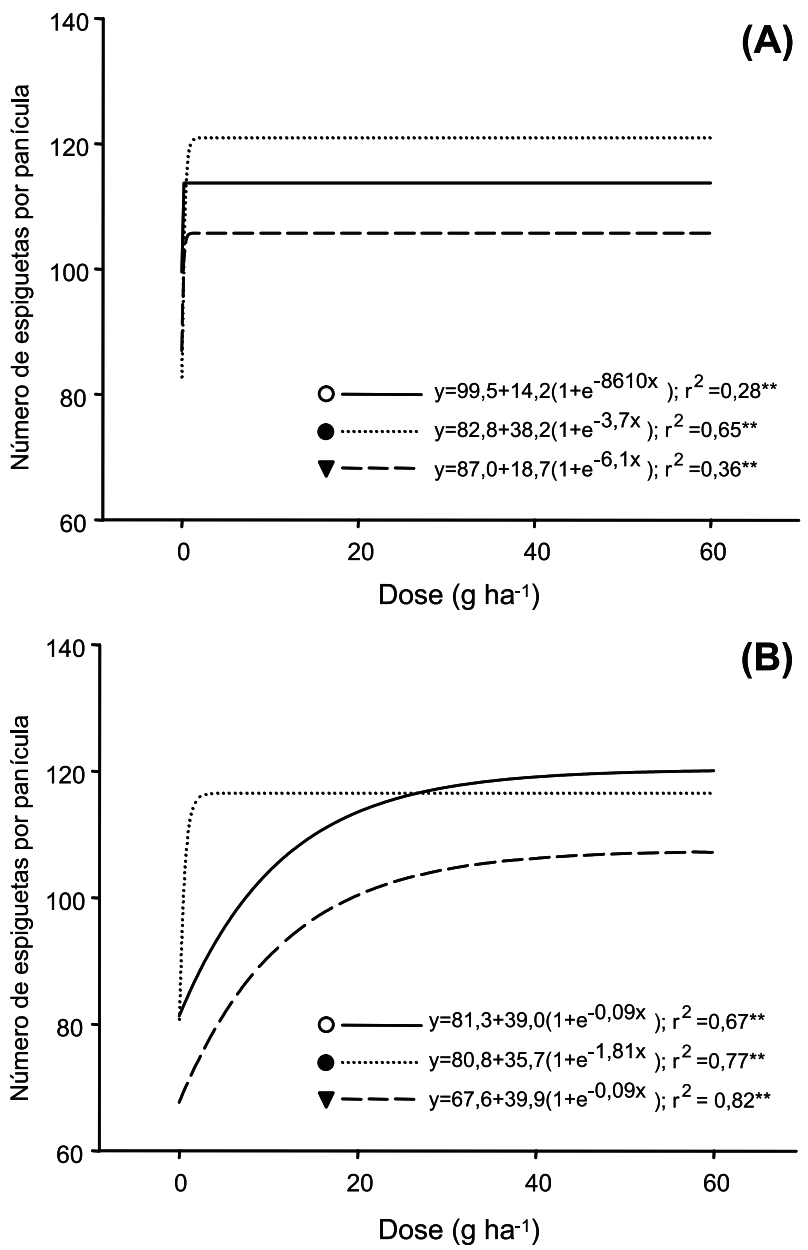

$r^{2}$ : coeficiente de determinação; significativo a $p \leq 0,10$.

Figura 4 - Número de espiguetas de arroz por panícula, cultivar Qualimax 1, em função das épocas de início da irrigação ( 1 DAT, O15 DAT e $\boldsymbol{\nabla} 30$ DAT), épocas de aplicação precoce (A) e tardia (B) e doses do herbicida penoxsulam. Granja Quatro Irmãos, Rio Grande-RS, 2005/2006.

\section{LITERATURA CITADA}

ADATI, C.; OLIVEIRA, V. A.; KARAM, D. Análise matemática e biológica dos modelos de estimativa de perdas de rendimento na cultura devido à interferência de plantas daninhas. Planta Daninha, v. 24, n. 1, p. 1-12, 2006.

AGOSTINETTO, D. et al. Interferência de capim-arroz (Echinochloa spp.) na cultura do arroz irrigado (Oryza sativa) em função da época de irrigação. Planta Daninha, v. 25, n. 4, p. 689-696, 2007.

ANDRES, A.; MACHADO, S. L. O. Plantas daninhas em arroz irrigado. In: GOMES, A.S.; JÚNIOR, A. M. M. Arroz irrigado no Sul do Brasil. Brasília: Embrapa Informação Tecnológica, 2004. p. 457-546. 
ANDRES, A. et al. Desempenho da cultivar de arroz BRS Pelota e controle de capim-arroz (Echinochloa spp.) submetidos a quatro épocas de entrada de água após a aplicação de doses reduzidas de herbicidas. Planta Daninha, v. 25, n. 4 , p. $859-867,2007$

BROWN, H. M. Mode of action, crop selectivity, and soil relations of the sulfonylurea herbicides. Pestic. Sci., v. 29, p. 263-281, 1990.

CONCENÇO, G. et al. Controle de plantas daninhas em arroz irrigado em função de doses de herbicidas pré-emergentes e início da irrigação. Planta Daninha, v. 24, n. 2, p. 303-309, 2006.

DAMALAS, C. A.; DHIMA, K. V.; ELEFTHEROHORINOS, I. G. Control of early watergrass (Echinochloa oryzoides) and late watergrass (Echinochloa phyllopogon) with cyhalofop, clefoxydim, and penoxsulam applied alone and in mixture with broadleaf herbicides.

Weed Technol., v. 20, n. 4, p. 992-999, 2006.

EBERLEIN, C. V. et al. Altered acetolactate synthase activity in ALS-inhibitor resistant prickly lettuce (Lactuca serriola).

Weed Sci., v. 45, p. 212-217, 1997

\section{EMPRESA BRASILEIRA DE PESQUISA}

AGROPECUÁRIA - EMBRAPA. Centro Nacional de Pesquisa Agropecuária de Solos (Rio de Janeiro, RJ). Sistema brasileiro de classificação de solos. Brasília: Embrapa Produção de Informação; Rio de Janeiro: Embrapa Solos, 2006. 412p.

FLECK, N. G. et al. Manejo e controle de plantas daninhas em arroz irrigado. In: VARGAS, L.; ROMAN, E. S. (Eds). Manual de manejo e controle de plantas daninhas. Bento Gonçalves: Embrapa Uva e Vinho, 2004. p. 251-321.

GALON, L. et al. Níveis de dano econômico para decisão de controle de capim-arroz (Echinochloa spp.) em arroz irrigado (Oryza sativa). Planta Daninha, v. 25, n. 4, p. 709-718, $2007 \mathrm{a}$.

GALON, L. et al. Estimativa das perdas de produtividade de grãos em cultivares de arroz (Oryza sativa) pela interferência do capim-arroz (Echinochloa spp.). Planta Daninha, v. 25, n. 3, p. $697-707,2007 \mathrm{~b}$

GOMES, A. S.; PAULETTO, E. A.; PETRINI, J. A. Arroz irrigado: manejo de água. Pelotas: Embrapa Clima Temperado, 1999. 16 p (Embrapa Clima Temperado. Circular Técnica, 16)
GOMES, A. S. et al. Manejo da água em arroz irrigado implicações e recomedações técnicas. In: PAULETTO, E. A et al. Manejo da água e do solo em arroz irrigado. Curso de Produção de Sementes de Arroz Irrigado - Módulo II. Pelotas: UFPel, 2005. 88 p.

JABUSCH, T. W.; TJEERDEMA, R. S. Partitioning of penoxsulam, a new sulfonamide herbicide. J. Agric. Food Chem., v. 53, n. 18, p. 7179-7183, 2005.

MENEZES, V. G.; RAMIREZ, H. Rendimento de grãos de arroz irrigado em função do início da irrigação e do controle precoce de plantas daninhas em Cachoeirinha. In: CONGRESSO BRASILEIRO DE ARROZ IRRIGADO, 3, REUNIÃO DA CULTURA DO ARROZ IRRIGADO, 25., Balneário Camboriú, 2003. Anais... Itajaí: EPAGRI, 2003. p. 190-192.

NEWHOUSE, K.; WANG, T.; ANDERSON, P. Imidazolinone-tolerant crops. In: SHANER, D. L.; O'CONNOR, S. L. (Eds.). The imidazolinone herbicides Boca Raton: CRC Press, 1991

OTTIS, B. V. et al. Rice weed control with penoxsulam (Grasp). Assoc. Access Eng. Spec. Res. Series, v. 517, n. 4, p. 144-150, 2003.

PANOZZO, L. E. et al. Métodos de manejo de Cyperus esculentus na lavoura de arroz irrigado. Planta Daninha, v. 27, n. 1, p. $165-174,2009$

PINTO, J. J. O. et al. Controle de capim-arroz (Echinochloa spp.) em função de métodos de manejo na cultura do arroz irrigado. Planta Daninha, v. 26, n. 4, p. 767-777, 2008.

SOCIEDADE SUL-BRASILEIRA DE ARROZ IRRIGADO - SOSBAI. CONGRESSO BRASILEIRO DE ARROZ IRRIGADO, 5.; REUNIÃO DA CULTURA DO ARROZ IRRIGADO, 27., 2007, Pelotas. Arroz irrigado:

Recomendações Técnicas da Pesquisa para o Sul do Brasil Pelotas: SOSBAI, 2007. 164 p.

SPRAGUE, C. L. et al. Palmer amaranth (Amaranthus palmeri) and common waterhemp (Amaranthus rudis) resistance to selected ALS-inhibiting herbicides. Weed Sci., v. 45, n. 2, p. 192-197, 1997.

ZABALZA, A. et al. Carbohydrate accumulation in leaves of plants treated with the herbicide chlorsulfuron or imazethapyr is due to a decrease in sink strength. J. Agric.

Food Chem., v. 52, n. 10, p. 7601-7606, 2004. 